\title{
INTIFADA AL-AQSA: VOCES DE MUJERES
}

\author{
ANA GARCÍA JIMÉNEZ Y EUNICE ORTIZ GARCÍA \\ Universidad Complutense de Madrid
}

\section{LA IMPORTANCIA DE LA PARTICIPACIÓN POLÍTICA Y SOCIAL DE LA MUJER}

Teniendo en cuenta que la mujer representa más del 50\% de la población mundial, necesariamente es un elemento determinante para la resolución de conflictos. Entre otros factores, uno importante para llegar a la igualdad de género y que muy a menudo falla en la sociedad de los países en desarrollo o desarrollados es que las mujeres no llegan al empoderamiento real. A menudo, la igualdad en las leyes no significa que en la práctica se realice. Esas leyes tienen que ir reforzadas por instituciones o sólidos mecanismos que permitan su verdadera puesta en marcha junto con un cambio social y de la tradición.

En ausencia de una mayor participación del hombre en los quehaceres domésticos y cuidado de la familia y debido a la falta de políticas sociales, toda responsabilidad exterior, como la implicación de las mujeres en la política, es una carga adicional que éstas no pueden asumir o pueden hacerlo muy a duras penas, significando una carga adicional para ellas. También existe un gran obstáculo, la llamada «barrera invisible» que impide a la mujer ocupar cargos de decisión y acceder a los centros de poder (en España e Italia, donde la igualdad en la representación política está reconocida por ley, el porcentaje de mujeres es mucho menor que el de hombres: en España, un 26,6\% de los escaños están ocupados por mujeres en el Parlamento, y, en Italia, un $9,1 \%)^{1}$.

La mujer tiende a buscar los puntos de convergencia y no de divergencia. La mujer aguanta en su vida muchas penas y sufrimientos a causa del papel que la sociedad le ha asignado por razón de género. Por consiguiente, la mujer es capaz de crear más empatía con respecto al enemigo en casos de conflictos.

La participación de la sociedad civil ayuda a asegurar que cualquier paz sea una paz duradera en situaciones post conflicto y juega un papel importante para resolver las causas estructurales profundamente arraigadas en los conflic-

1. Informe de Desarrollo Humano 2002, A1.2 «Indicadores objetivos de gobernabilidad», p. 42.

Feminismo/s, 3, junio 2004, pp. 191-205 
tos. Mujeres israelíes y palestinas coincidieron en una reunión del Consejo de Seguridad de la ONU en que cualquier negociación futura en Oriente Medio necesita forzosamente incluir a la sociedad civil, especialmente a las mujeres. Sin olvidar que, según el Banco Mundial, la participación política de la mujer en los países reduce el riesgo de corrupción ${ }^{2}$.

Se puede decir que la sociedad civil no considera la participación de la mujer tan importante como la del hombre (a pesar de que ellas son las grandes amortiguadoras de las crisis, pilares indispensables de la resistencia y grandes promotoras de los contactos con los israelíes). Mientras la mujer no cambie la división tradicional de las labores, no se llevarán a cabo transformaciones en la estructura social. Según Sahar Khalifeh: "En cualquier caso, la responsabilidad para cambiar percepciones sociales respecto a la mujer descansa en los hombros de las mujeres» ${ }^{3}$.

La familia extensa patriarcal que se da en Palestina (sobre todo en Gaza) interioriza y reproduce la subordinación femenina. El poder de la mujer se adquiere con la edad y mediante la cría de hijos varones. En la mujer reside, en los momentos de crisis, la enorme responsabilidad de mantener y perpetuar la cultura y la tradición, así como la reproducción de la sociedad misma, convirtiéndose en verdaderas fábricas de futuros luchadores ${ }^{4}$.

\section{BREVE RECORRIDO SOBRE LA PARTICIPACIÓN POLÍTICA DE LA MUJER PALESTINA}

Hasta mediados del siglo XX, la sociedad palestina era rural y tradicional, la mujer apenas salía de la esfera doméstica y tenía escasa influencia en el ámbito social y aún menos en el político. Una serie de acontecimientos históricos como el final del Período Otomano, el Mandato Británico de 1927 a 1948, el inicio de la inmigración judía, el éxodo rural y los primeros focos de industrialización dan comienzo a un cambio en la vida de la mujer. Poco a poco empieza a acceder a niveles más altos en su educación.

Sin embargo, las transformaciones más visibles empezaron con la diáspora palestina entre 1948 y 1949: la guerra y la ocupación sionista forzaron a la mujer a intervenir en el espacio público, el trabajo y la política. Este hecho contribuyó a que cambiaran la opinión sobre sí mismas y el juicio que sobre ellas tenía el resto de la sociedad.

2. BANCO MUNDIAL: Informe del BM sobre investigaciones relativas a políticas de desarrollo, 1995: "Hacia la integración de sexos en el desarrollo económico» (www.worldbank.org/gender/ prr).

3. Khalifeh, Sahar: "Comments by five women activists. Siham Abdullah, Amal Kharisha Barghouthi, Rita Giacman, May Mistakmel Nassar, Amal Wahdan», en Suha Sabbah (ed.): Palestinian women of Gaza and the West Bank, Blooming and Indianapolis, Indiana University Press, 1988, p. 215. Novelista palestina. Varias de sus novelas han sido traducidas a diversas lenguas. Es profesora de la Universidad de Bir Zeit, en Ramala, y ha fundado en Nablus un Centro de asuntos de la mujer.

4. Arjonilla, Sofía: La mujer palestina en Gaza, Guadarrama, Ediciones del Oriente y del Mediterráneo, 2001. 
La sociedad palestina es patriarcal, en ella existe una fuerte división sexual $y$ de funciones. La mujer es ante todo madre y ama de casa, y a pesar de ser considerada elemento secundario y estar sometida, soporta el peso de reforzar los valores familiares.

El principal problema de las mujeres palestinas desde hace más de cincuenta años es el de la supervivencia y la lucha cotidiana contra la ocupación militar israelí, las guerras y la violencia del Estado de Israel. La participación activa en la lucha contra la ocupación es aceptada por las mujeres, de modo que se plantea el dilema entre dar prioridad a la lucha por la defensa de sus derechos como mujeres o la necesidad de luchar como parte del pueblo palestino por la liberación nacional. Como dice Suheir Azzouni Mahshi, primera directora del Al Lagna Attaqaniyya li Su'un al mar'a (Comité Técnico de Asuntos de la Mujer): "las mujeres de mi tiempo tienen que hacer frente a dos formas de opresión: la ocupación israelí y la dominación de la sociedad patriarcal $»^{5}$. La lucha de las mujeres palestinas atraviesa seis etapas que trataremos a continuación.

\subsection{Desde la fundación del movimiento sionista (1882) hasta la creación del Estado de Israel (1948)}

La fecha exacta del comienzo de la actividad política de las mujeres palestinas no está clara, aunque algunas fuentes indican que fue en 1884 cuando participaron en la primera manifestación junto a los hombres contra el primer asentamiento judío cerca de Afúlah ${ }^{6}$. Debido a las condiciones sociales de ese momento y al conservadurismo de principios de los años veinte, la participación de la mujer era limitada.

Las primeras asociaciones de beneficencia, cooperativas, culturales, comunitarias y confesionales palestinas se crearon en el período otomano, cuando se promulgó la Primera Ley de Asociaciones, pero muy pronto los movimientos institucionales se vieron afectados por la política nacionalista: la lucha contra la colonización sionista y la demanda de autodeterminación.

Aunque los movimientos de mujeres recién instaurados intentaban pasar desapercibidos, actuaban de forma sutilmente subversiva y, con el tiempo, terminaron siendo manifiestamente feministas, en el sentido contemporáneo del término. A pesar de que su trabajo se centraba en lo social y caritativo, las mujeres emprendieron un camino claramente político, si bien dentro de los movimientos nacionalistas sólo fueron consideradas como una fuerza de apoyo. La mayoría de las mujeres que participaban en los movimientos pertenecían a las clases cultivadas alta y media, la elite de Palestina.

5. Mahshi, Suheir Azzouni: «A Free Palestinian, a Free Woman», Palestine- Israel Journal of Politics, Economics and Culture, 3 (1995), p. 8.

6. KazI, Hamida: "Palestinian Women and the National Liberation Movement: A Social Perspective»., en Women in the Middle East, New Jersey, Khamsim, 1987, p. 27. 


\subsection{Desde el establecimiento del estado de Israel (1948) a la ocupación de Gaza y Cisjordania (1967)}

El movimiento de mujeres fue especialmente activo en esta época. Sus miembros seguían perteneciendo a la burguesía. Su papel continuaba limitado a actividades sociales y caritativas, tales como el mantenimiento de centros de formación profesional para dotar a las mujeres de formación con el fin de que pudieran integrarse en el mercado laboral ${ }^{7}$.

Las diferentes organizaciones femeninas se enfrentaron a numerosos obstáculos y restricciones políticas impuestas por los gobiernos jordano, egipcio y sirio. A pesar de ello, la mujer palestina se mantuvo activa políticamente, además de trabajar con las organizaciones benéficas y religiosas existentes -se crearon al menos seis para tratar principalmente las necesidades de los refugiados-. La educación de las niñas fue una de sus prioridades.

Se atisban los primeros cambios en las relaciones entre hombres y mujeres relacionados con el debilitamiento de la familia, la institución social más poderosa en la sociedad palestina, como resultado del desastre de 1948, la dispersión y el espíritu de trasformación política y social que alimentó el nacionalismo árabe. La nueva realidad política, junto con la gran importancia concedida a la educación (incluyendo la de la mujer) y la difícil situación económica, que hizo que la supervivencia de muchas familias dependiera del trabajo de la mujer fuera de casa, facilitaron el desarrollo de la conciencia política de ésta e inspiraron nuevas formas de resistencia. Para miles de mujeres de las clases medias, fue la primera oportunidad de desarrollar unas actividades hasta entonces reservadas a los hombres.

\section{3. $1967-1975$}

La lucha armada es la protagonista de este período. La ocupación israelí en 1967 produjo un cambio drástico en la vida de las mujeres y provocó su participación en la resistencia política. Surgieron organizaciones armadas cuyos miembros eran mujeres de la burguesía, educadas y libres de tareas domésticas; la mayoría provenían de las familias prominentes de Palestina.

Su papel en la resistencia no se limitaba a abastecer de comida y armas a los fedayin sino que se involucraron en operaciones armadas. Se produjo un cierto grado de especialización en función de la localización geográfica de la ocupación, por ejemplo: en Gaza, las mujeres eran las encargadas de lanzar granadas contra vehículos militares y sedes oficiales del gobierno militar israelí y confeccionaban explosivos y cócteles molotov que luego arrojaban en lugares estratégicos ${ }^{8}$.

Las mujeres palestinas en Israel, influidas por esta nueva realidad, se afiliaron a los partidos políticos e incrementaron su participación en diferentes aspectos de la vida social. Por ejemplo, de 1969 a 1972 el número de mujeres

7. KaZI, Hamida: Op. cit. 
estudiantes árabes en universidades israelíes aumentó el doble que los estudiantes hombres.

La mujer por primera vez fue admitida como dirigente en las organizaciones de resistencia y luchó junto al hombre, aunque en el grupo de Fatah, tanto en mítines como en formaciones militares, eran rechazadas. Los programas de movilización comenzaron en los campos de refugiados donde la mujer fue reclutada dentro de la infraestructura social del movimiento de resistencia de la OLP.

\subsection{5-1987}

Se reconoció por primera vez el derecho de voto a la mujer en las elecciones de 1976, pero no se le permitía la actividad política. Existían organizaciones de estudiantes, en las cuales se incluía a mujeres, que elegían a sus dirigentes democráticamente y de forma descentralizada.

Desde finales de 1970 hasta principios de 1980, mujeres activistas, estudiantes y obreras, crearon comités de mujeres diferentes a los ya existentes. Sus objetivos se distanciaban de las tradicionales actividades asistenciales de las asociaciones de mujeres. Dieron prioridad a organizar y formar a las mujeres y llevar a cabo proyectos para generar ingresos9. En septiembre de 1988 los comités populares fueron declarados ilegales por las autoridades israelíes y esto hizo que aumentara la unión y la cooperación entre ellos.

\subsection{De la primera Intifada (1987-1991) a la segunda Intifada (2000)}

La primera Intifada cambió la vida de las mujeres. Lucharon contra la ocupación israelí y contra las normas que les imponía su entorno. Desempeñaron un papel muy activo en manifestaciones no violentas, huelgas, elaboración de panfletos y sobre todo en la estabilidad de su hogar. Cuando los líderes de la sublevación fueron detenidos o exiliados, asumieron un papel de liderazgo.

Esta movilización hizo que madurasen las organizaciones de mujeres y adquiriesen sus formas más modernas. Ampliaron sus actividades y ganaron visibilidad. Modificaron sus prácticas y buscaron nuevas formas de intervención.

La Intifada fue el principal catalizador de la movilización masiva de la mujer. Participaron directamente en el combate, ayudaron en los campos de refugiados y dirigieron sus actividades hacia zonas rurales, proporcionando ayuda a las mujeres del campo. Se unieron para la causa común. Se enfrentaron a los soldados en defensa de sus hijos y maridos y, cuando éstos eran hechos prisioneros, se hicieron cargo de la manutención de la familia y de las visitas a los prisioneros, que exigían mucha dedicación: largas colas, humillaciones, golpes...

Las mujeres palestinas consolidaron y extendieron los nuevos comités populares, que adquirieron gradualmente una infraestructura altamente especializada. En el panorama político apareció una generación de mujeres activistas

8. Al-TAwra Al-Wahidi, Maysun: Al-mar'a al-Filistiniyya wa-l- 'ittilal al-'isra'ili, Amman, Dar al galil li-l-nasr wa-dirasat wal-sabhat al-Filistiniyya, 1987, pp. 22.

9. Barreñada, Isaías: "Mujeres palestinas: Protagonismo y relegación», Nación Árabe, 44 (2001), p. 61. 
jóvenes y politizadas que desafiaban al hombre en el trabajo público, que hasta entonces era exclusivamente masculino. También crearon comités de educación que sustituían a las escuelas que las autoridades comenzaron a cerrar considerando que eran centros de adoctrinamiento político. La participación de la mujer fue disminuyendo a medida que la Intifada fue perdiendo espontaneidad y se institucionalizó. El efecto más significativo fue la transformación de su rol. La sociedad las apoyó "temporalmente» y les reconoció ese desafío en nombre de la causa nacional.

Las mujeres lucharon para transformar la sociedad tradicional. En los Acuerdos de Oslo pidieron la eliminación de todas las formas de discriminación de la mujer y la garantía de la igualdad en política, derechos civiles, oportunidades en el trabajo, educación, derechos personales, protección contra la violencia y toma de decisiones, pero no lo consiguieron. El interés por la mujer quedó relegado y primaron los asuntos nacionales. Cinco años después de la Intifada, la falta de una solución política a la ocupación, el desastre económico tras la Guerra del Golfo y la aparición de movimientos fundamentalistas provocaron la vuelta de la mujer a las viejas normas de patriarcado.

\subsection{Desde $\mathbf{2 0 0 0}$ hasta nuestros días: Intifada Al-Aqsa. Voces de mujeres: realidades y sueños}

El análisis de este período está aún por hacer. La proximidad de los acontecimientos y la cada vez más compleja situación en Oriente Medio nos han inclinado a dar la palabra a mujeres que viven en el interior del conflicto. A preguntas sobre cómo resolverían el conflicto, cómo ven los cambios de la participación de la mujer en esta Intifada y la primera, sus deseos, etc., sus respuestas son un reflejo de su situación y la del conflicto. Son voces de mujeres con estudios, iletradas, antiguas alumnas, amigas, mujeres que se han puesto en contacto con otras mujeres y con nosotras gracias a un amigo periodista, a un amigo de Nablús y a un amigo virtual, el e-mail ${ }^{10}$. Muchas de ellas nunca han sido escuchadas ni tenidas en cuenta, aquí tienen un espacio.

\subsubsection{Zahira Kamal}

Es la titular del ministerio de Asuntos de la Mujer creado por el nuevo Gabinete de Abú Alá. Nació en Jerusalén en 1945. Estudió Física en la Universidad de Ein Shams de El Cairo. Fue profesora en el Centro de Enseñanza para Mujeres de Ramala de la UNRWA. Entre 1990 y 1993 dirigió el principal Comité del Frente Democrático para la Liberación de Palestina en el que militó durante diez años. Ahora pertenece a FIDA, la Unión Democrática Palestina, y es miembro de su Comité Ejecutivo. Fue directora de Programas de la Oficina de Desarrollo de la Mujer del UNDP en Jerusalén entre 1993 y 1995. Estuvo a la cabeza de la Dirección General de Planificación de Género y Desarrollo en el ministerio de AAEE palestino. En 1996 fundó el comité interministerial de coordinación para

10. Entrevistas realizadas en noviembre de 2003. 
el progreso de la mujer palestina. Cofundadora y presidenta de la Federación palestina para la Acción de la Mujer, la primera organización de mujeres en los territorios ocupados.

Estuvo en la cárcel con detención administrativa durante seis meses en 1979, y en arresto domiciliario entre junio de 1980 y marzo de 1987, y de junio de 1990 a julio de 1991. Zahira participó en el Consejo de Asesoramiento de la Delegación palestina en la Conferencia de Paz en Oriente Medio y participó en las reuniones de Madrid, Washington y Moscú.

Zahira fue una de las dirigentes de los comités populares en la primera Intifada. Destaca la labor que desempeñó la mujer en la primera Intifada:

"La mujer participó en la primera Intifada de muchas maneras, en la lucha contra la ocupación, en particular en los comités populares que se establecieron para superar los obstáculos que imponía el Ejército, como el toque de queda. La mujer enseñaba a los niños que no podían ir a la escuela, participó en la distribución de comida en las casas, cuando la gente no podía salir a comprar. En las manifestaciones también tenía una presencia importante.»

"Las mujeres que participaron en la primera Intifada y que desempeñaron papeles de liderazgo ahora trabajan en el sector privado o en los ministerios. Por ejemplo yo, y Suhan Barguti en el ministerio de Administración Local».

«En esta segunda Intifada la participación popular es menor y es más violenta, y la ocupación está a las puertas de la ciudad, no tanto dentro, con lo que el papel de la mujer es menor en el enfrentamiento directo, pero mantiene la estructura social, la unidad de la familia cuando se registran muertos o detenciones, ella es la que permanece en casa y da fuerza y cuida a los demás. Cuando destrozan una casa, la mujer es la que tiene que rehacer el hogar en una tienda de campaña, es el motor de la familia y la sociedad. Sin ella el impacto de las agresiones sería mucho mayor».

No obstante, Zahira cree que, en general, la importancia de la mujer ha cambiado y podría decirse que ha disminuido en esta Intifada: "Las mujeres hoy intentan participar en todos los debates políticos de la Autoridad Nacional Palestina (ANP), en particular en las nuevas leyes que se elaboran en el Consejo Legislativo Palestino y en especial la redacción de una Constitución que otorgue a las mujeres los derechos que se merece».

Las mujeres más jóvenes no quisieron involucrarse en política en la primera Intifada, porque era mal visto por la sociedad y por los jóvenes de su edad, que incluso llegaron a romper compromisos y a no querer casarse con chicas politizadas porque creían que participaban en la resistencia para verse con hombres, mientras que las mujeres mayores, madres casadas, socialmente no tenían nada que perder, ya habían conquistado una situación en la sociedad y no tenían miedo al rechazo social. Sobre ello dice:

«El problema de las mujeres activistas que luego no son bien vistas por la sociedad al haber salido del ámbito doméstico no es un fenómeno que sólo tenga lugar aquí. Muchas activistas se casaron con chicos que también lo eran y con los que compartían su activismo. Al revés, quizá, el activismo fomenta el contacto con los hombres y las relaciones con ellos». 
Reconoce que "puede que haya habido un retroceso en la aceptación de la mujer activista debido al auge de la religiosidad, fenómeno que se suele producir en las sociedades en conflicto".

En cuanto a las mujeres que han llevado a cabo ataques suicidas, afirma:

"la clave es si ellas son enroladas por otros o lo hacen empujadas por el dolor. Puede que sea reflejo de mujeres que se sienten responsables de su destino, con capacidad de decidir por sí mismas. Pero no creo que podamos hablar de las mujeres que llevan a cabo ataques suicidas como un fenómeno, por el momento, son sólo casos limitados y espero que no continúen».

Considera que, en general,

"la mujer tiene capacidad para escuchar y entender la postura del otro y convencer. Pero su capacidad de resolver conflictos hasta ahora no ha sido puesta a prueba, y debería serlo. Por lo general, la mujer prefiere negociar a recurrir al enfrentamiento. Creo que podemos hacer que las cosas cambien. La mujer palestina tiene experiencia en la lucha desde principios del siglo pasado. Es la que tiene el nivel de educación más alto de todo el mundo árabe y también la que más ha sufrido y ha sido forzada a entrar en la lucha. Los dirigentes palestinos han reconocido esa labor tanto en la declaración de independencia de 1988, en Argelia, como en la Ley Básica de la ANP. Las mujeres participamos al más alto nivel en las negociaciones, en particular Hanan Asharaui, Suad Amer y yo en las negociaciones de Washington 1992-1994, lo que no fue el caso entre los negociadores israelíes. La creación de un Ministerio de la Mujer es una exigencia desde 1994, en particular del Comité Interministerial para el Progreso de la Mujer y el Sindicato General de la Mujer Palestina».

Expresa decepción por la pobre representación de la mujer en el Parlamento, tan sólo 5 de los 88 miembros. Quiere introducir en la Constitución una cuota de un mínimo obligatorio de parlamentarias.

\subsubsection{Fadua Barguti}

Es abogada, su ámbito de trabajo son los derechos humanos, la mujer y los prisioneros. Nació en la aldea de Kubar, a 14 kilómetros de Ramala, en 1964. Titulada en Derecho por la Universidad Árabe de Beirut. Ahora prepara un Master en Derecho en la Universidad Abierta de Jerusalén. Ha sido activista en cuestiones de la mujer desde los 20 años. Entre 1987-94 vivió entre Ammán y Ramala cuando su marido, Maruán Barguti, fue expulsado a Jordania ${ }^{11}$. Formó parte de los Comités de Mujeres de Trabajo Social, fue una de sus fundadoras y continúa en el comité ejecutivo de esa organización. Ahora trabaja de abogada y durante los dos últimos años se ha especializado en los casos de presos palestinos en cárceles israelíes. Tiene una hija y tres hijos.

"La primera Intifada fue un levantamiento popular, eso permitió una mayor participación femenina. La mujer entonces trabajaba de manera más organizada. En esta Intifada, Israel ha impuesto otro tipo de lucha, nos ha forzado a recurrir a la violen-

11. Maruán Barguti es diputado y secretario general del movimiento al Fatah Actualmente está encarcelado en una prisión israelí. 
cia. Ahora la mujer sigue participando pero individualmente. Sigue participando porque no hay nadie que no esté afectado por la opresión, con los arrestos, las muertes, la demolición de casas y destrucción de tierras. A las organizaciones de mujeres les ha faltado un plan de actuación y esto ha sido un fallo. En la primera Intifada todos podían participar; ahora, con el énfasis en la lucha armada, no. La presencia de la mujer ha disminuido. Pero, al final, el peso de la Intifada recae sobre la mujer.»

«Las mujeres en la primera Intifada convencieron a la sociedad de que también ellas tenían un papel que desempeñar en la lucha. Y, sin embargo, es verdad que ahora la mujer no desempeña el papel que debería en la sociedad. Tenemos un número de diputadas muy reducido, y nuestras costumbres, que limitan a la mujer al ámbito doméstico, continúan en pie. Ha aumentado la religiosidad. Pero tenemos derecho a ser más, a participar en el liderazgo palestino. Será un problema si en las próximas elecciones la importancia de la mujer no se refleja; en particular la mujer palestina debe comenzar a estar en una posición de poder tomar decisiones.»

«Sí ha habido una regresión desde la primera Intifada para la mujer. La sociedad palestina ha aceptado que la mujer luche y muera y que sea detenida, pero no que lidere la sociedad y tome decisiones. Ha habido, además, una debilitación de las asociaciones de mujeres, lo que tendrá a corto plazo resultados negativos. Han fracasado en ofrecer a la mujer un programa de cómo luchar, cómo participar en la lucha de forma organizada y no sólo individualmente. Y eso que la mujer palestina está dispuesta a luchar. Las asociaciones de mujeres deberían haber ayudado más a las mujeres, que son las que cargan al final con el peso de la Intifada. Tendrían que haber ayudado a las mujeres que han perdido a sus maridos y sufren la pobreza. Más de la mitad de la población palestina vive por debajo del umbral de pobreza».

\subsubsection{Rita Giacaman}

Es profesora de Salud Pública en la universidad de Birzeit, Ramala. Es una de las veteranas del activismo por una Salud Pública en Palestina. También es una de las figuras de los comités de mujeres durante la primera Intifada. Es autora de numerosos artículos sobre la mujer palestina y los asuntos sociales. A la pregunta de qué tres cosas piensa que podrían solucionar el conflicto responde:

«Por parte israelí, la admisión de lo que ocurrió en 1948, de modo que Israel pueda entender que los palestinos han hecho ya su compromiso histórico al aceptar la solución de los dos estados, y de esa manera puedan dirigirse hacia el mismo objetivo, aunque esto no parece una buena opción, puesto que Sharon piensa que probablemente lo que ocurrió en el 48 puede volver a ocurrir en el siglo XXI. Segundo, un verdadero cambio en nuestra política para que pueda funcionar como un verdadero árbitro, y no como portavoz del lobby judío, y tercero, un papel más fuerte de Europa y la ONU para ayudar a que las cosas vayan en la buena dirección $\mathrm{y}$, esperemos, hacia el final del conflicto.»

«Si gobernara, consultaría constantemente con mi pueblo, trabajaría por un mejor entendimiento sobre lo que es realizable y lo que no lo es, me dedicaría seriamente a acabar con la corrupción e impulsaría el sistema político hacia el siglo XXI, y no hacia el siglo XIX y la sociedad patriarcal y tradicional, como ha sucedido desde la instauración del régimen de la ANP».

¿Hacia dónde se dirigen las nuevas generaciones de mujeres? 
«En los últimos años de la década de los noventa la lucha fue más débil que en los ochenta, y aumentó el conservadurismo. En general, se aprecia que hay una mayor participación en las mujeres maduras que en las jóvenes. Éstas están creciendo en un vacío de acción y con un conservadurismo en alza. Puede que sus vidas y futuro sigan más la dirección de lo que la sociedad espera que el camino de su emancipación. Aun así tengo esperanza, pues un mayor número de mujeres está accediendo a la formación, especialmente de nivel superior. Esto, junto con el trabajo fuera del hogar, será crucial para el desarrollo futuro».

Sobre la participación política de las mujeres en esta Intifada dice: «La participación ahora es diferente, las condiciones no permiten lo que ocurrió entonces en la primera. Siendo realistas, las estructuras de la autoridad palestina no permiten a la mujer que participe formalmente en el proceso de paz".

Y concluye manifestando cuáles serían sus deseos: «Un futuro mejor para mi hija de 13 años y para los jóvenes de Palestina que el de mi madre y el mío... No tengo más deseos... Triste ¿verdad? Pero así están las cosas...»

\subsubsection{X, estudiante}

Estudiante de química y biología, natural de Al Nusaira, actualmente está realizando su doctorado en Salamanca en Microbiología Genética. Sobre la diferente participación de la mujer entre la primera y la segunda Intifada dice:

«En esta Intifada, hay cambios, como por ejemplo, en la educación y en la política. El número de las mujeres que están estudiando en las universidades es mayor que durante la primera Intifada. Además, ahora hay mayor participación de mujeres en los partidos políticos. Después de la primera Intifada y antes de la segunda, las mujeres empezaron a salir de lo tradicional, pero, cuando empezó la segunda, volvieron otra vez como antes o un poco peor.»

«En primer lugar, el problema está metido en las cabezas de los radicales de los dos lados, tanto israelíes como palestinos. Tenemos que aprender a vivir juntos y los israelíes tienen que abandonar su sueño del Gran Israel. ¡Del Nilo hasta el Tigris! Y los radicales palestinos, dejar su sueño de echarlos al mar. Si Israel sale de los territorios ocupados en 1967, en ese momento podremos vivir juntos».

Cuando se le pide que formule tres deseos, concluye: "Mis tres deseos son una vida mejor para el pueblo palestino, más libertad para sus mujeres y, por último, uno personal, conseguir una beca para poder terminar mi doctorado».

\subsubsection{Nur}

Es farmacéutica, nació en Kuwait y vive en Nablus. Opina que para terminar con el conflicto hay que «estrechar nuestra relación con Dios, aumentar nuestra creencia en nuestros derechos nacionales y crear nuevos métodos para continuar nuestra lucha hasta deshacernos de los israelíes.

Como actividades para ayudar a su pueblo, sugiere:

«aprender más sobre nuestros enemigos, aprender informática y lenguas extranjeras para poder explicar y comunicar nuestros puntos de vista al mundo. Por último, más implicación en la educación, salud y religión. La gente educada sabe reaccionar mejor en momentos difíciles, y, respecto a la salud, en esta Intifada nos hemos dado 
cuenta de lo importante que son los problemas de salud, la gente sana tiene mente sana y buenas ideas para alcanzar nuestra libertad como pueblo, y, respecto a la religión, es importante obedecer a nuestro Dios y pedir justicia al mundo... Si fuera gobernante nunca perdonaría a Israel lo que está haciendo con el pueblo palestino y haría un plan para liberar a Palestina».

\subsubsection{Rasha}

Acaba de terminar sus estudios de Farmacia en la universidad de Nablus, ahora está en París con una beca del gobierno francés. Tiene un hermano que vive con sus padres en Nablus y lleva dos años sin salir de casa a causa de una fuerte depresión por las detenciones del ejército israelí sobre la población joven. Tiene miedo. Se esconde en un piano cuando el ejército entra en las casas. Rasha dice que para acabar con el conflicto es necesario un diálogo para la paz verdadera, olvidar, y un Estado para dos pueblos. Durante esta Intifada, ella y su madre montaron un pequeño colegio y daban clases a niños durante los toques de queda tan continuos. Dice que hay que continuar educando bajo toque de queda, continuar con los estudios $y$, sobre todo, no emigrar.

Si ella gobernara, haría un solo Estado para dos pueblos donde los ciudadanos tuvieran los mismos derechos y deberes, donde hubiera una verdadera democracia.

Respecto a la participación de las mujeres en esta Intifada dice que están participando más, ya que la situación es más dura y a todo el mundo le atañe de una manera u otra. Sus tres deseos son: obtener un doctorado, vivir en paz y realizar algo grande para la humanidad.

\subsubsection{Lama}

Joven palestina nacida en Arabia Saudí, vive en Nablus, no trabaja. Lo que más desea es vivir en paz, despertarse un día y que los tanques israelíes hayan desaparecido de las calles y de las carreteras y que acaben de una vez por todas los toques de queda. Quiere vivir como el resto del mundo, y que haya derechos humanos. Dice que las mujeres palestinas siempre se sacrifican, ellas son madres, esposas y hermanas de los palestinos que luchan y mueren. Lama insiste en que está muy orgullosa de ser una mujer palestina.

\subsubsection{Samar}

Acaba de terminar Ingeniería Industrial en la universidad de Nablus, vive en Qalquilia. En la actualidad se encuentra en España.

"Lo primero que hay que hacer para acabar con el conflicto es cambiar a los primeros ministros palestino e israelí, ésta es la condición más importante para que se pueda comenzar a negociar; segundo, negociar con todos los movimientos políticos de Palestina y no sólo con la ANP y, sinceramente, como mujer de Qalquilia y estudiante en Nablus, no creo que termine el conflicto, sólo podría acabar de una manera: con el fin de Israel.

»He ayudado a mi hermana pequeña y a otros niños durante los toques de queda a entender la situación, les he explicado lo que escuchan y ven en las noticias, en las 
calles, les he dado ánimos, les he ayudado a enfrentarse a las imágenes difundidas por los medios, a que no convivan con el miedo. He hablado con gente que no es palestina y he intentado mostrarles la verdadera imagen de lo que vemos y vivimos cada día y noche. La gente necesita ayuda psicológica, siempre escuchan noticias de muertes, de heridos. Alguno puede ser de tu familia, esto es una tensión continua. Necesitamos ayuda en este aspecto. Hablar y animar a la gente parece que da un poco de esperanza».

Si ella fuera Arafat, "acabaría inmediatamente con mi trabajo como primer ministro. Arafat ya ha tenido bastante tiempo para hacer lo que ha podido y ha enseñado al mundo que ya no puede hacer más, así que tiene que irse».

"Creo que la mujer ahora participa de una manera más fuerte, también la Intifada es más violenta, ha habido mujeres que han hecho operaciones suicidas... Deseo que termine el conflicto y que Palestina obtenga mejores condiciones que hasta ahora, que pueda realizar más cosas por mi pueblo porque lo hecho hasta ahora es muy poquito y no ver más el nombre de Israel en los mapas».

\subsubsection{X, 56 años}

Nació en Al Abbassya (hoy Israel, cerca de Haifa), vive en Nablus. Con 15 años enseñaba árabe a los niños de preescolar, se casó a los 16, tiene diez hijos. Cuando se instaló en Nablus, comenzó la primera Intifada y sus hijos fueron los primeros del barrio en ser arrestados y torturados. A uno de sus hijos lo mataron, y a otro, lo mandaron a otro país. Ahora, con esta Intifada, la vida se ha dispersado. Por culpa de los check points (puestos militares de control) la gente se siente extranjera en su propio país. Está orgullosa porque ha podido dar educación universitaria a todos sus hijos.

Para solucionar el conflicto propone

«desarrollar los medios de comunicación palestinos para que la verdad sea accesible al mundo entero, enseñar todos los aspectos de esta represión, mostrar la realidad de los palestinos y la verdadera cara de la ocupación. También liberar a todos los pueblos árabes y detener la cooperación económica y política, y todos los intereses con el Estado ocupante, y que la nación árabe se una contra la ocupación y, de esta manera, ayudar a los palestinos a acabar con el conflicto. Por último, la vuelta de los refugiados, de todos los refugiados, y que se les indemnice».

Durante esta Intifada ha ayudado a su pueblo:

«He llevado comida y ropa a los prisioneros, todo pagado de mi bolsillo. He llevado información sobre los prisioneros a sus familiares. He socorrido a heridos, he distribuido medicamentos y comida, he recibido y he dado información a la prensa extranjera sobre lo que ocurre, sobre nuestro pueblo y nuestra religión... Si gobernara sería honesta con mi trabajo, crearía métodos limpios para la resistencia, desmantelaría los asentamientos, los check points y, por último, apoyaría y animaría la libertad de religiones en Palestina y, sobre todo, no abandonaría Jerusalén.»

Sobre la participación de la mujer dice que: «la participación y la cooperación en la primera Intifada fue mucho mayor entre la gente que vive en Cisjordania: la primera Intifada fue dirigida por el pueblo, la segunda, por jefes políticos». 


\subsubsection{Jihane Hokmat al Masri}

Vive en Nablus, es directora de la Asociación de Ayuda Familiar. Respecto a la participación de las mujeres dice que

«en la primera las mujeres llegaron incluso a posiciones de liderazgo, porque el movimiento nacional admitió el papel de las mujeres que organizaban la resistencia interna en los comités de barrios y porque todas las actividades eran secretas y, además, los soldados israelíes hacían redadas de hombres y sólo dejaban a las mujeres. Pero en esta Intifada, la situación es muy diferente por la existencia de la Autoridad Palestina. Los acuerdos de Oslo no pusieron fin a la ocupación, sino que la vistieron con una nueva ropa: la salida del ejército de las ciudades. Sin embargo, los soldados siguen en las ciudades pero en los check points a la salida de las ciudades, lo que ha hecho que disminuya la participación de la mujer».

«Sin duda las mujeres en las dos Intifadas han tenido un papel muy importante, rompiendo los bloqueos impuestos: salen fuera de casa, participan en la resistencia... Pero los conceptos culturales no reflejan su papel para darles una posición social, económica y política merecida, al contrario, tienen que enfrentarse a la discriminación a todos los niveles, en la casa, en el trabajo y, sobre todo, en lo referente a los salarios $y$ las condiciones de trabajo».

"En esta Intifada existe un factor muy importante que ha tenido un impacto muy negativo en las mujeres en particular y la sociedad en general: el miedo. Este miedo que, debido a los bloqueos, a los toques de queda, a las situaciones extremas de violencia, se ha reflejado en la familia, y a causa de la autoridad tradicional que ejercen los hombres sobre las mujeres, y que les exige la protección familiar, ha sido fatal para éstas. Las que estudian, pero viven fuera de las ciudades, han dejado de asistir a clase por el miedo de los padres a los check points, y la consecuencia de esto es que de nuevo casen a las chicas muy jóvenes. De la misma manera, si los cheks points están muy alejados de las ciudades las mujeres no participan. En cambio, en el interior de las ciudades, el papel de la mujer es muy importante, sobre todo en los temas asistenciales (primeros auxilios, urgencias, hospitales móviles...»

Y concluye:«El círculo de violencia entre palestinos e israelíes no se acabará hasta que no se establezca un Estado palestino en el territorio de 1967, con Jerusalén como capital y la admisión del derecho al retorno de los refugiados palestinos y su indemnización correspondiente».

\subsubsection{Samar Hawach}

Tiene 45 años, es presidenta de la Asociación de mujeres palestinas que trabajan para el desarrollo.

«Durante esta Intifada la participación de la mujer ha cambiado, la situación no es la misma, durante la primera Intifada no había autoridad palestina, y muchos aspectos de la vida social estaban en manos de la gente... El papel de la mujer en esta Intifada es más a nivel privado. En esta Intifada las mujeres mayores participan a nivel asistencial, hay muchísimos mártires y heridos. Muchas han perdido a sus hijos, y su participación ha disminuido». dice:

Respecto a la participación de las mujeres jóvenes en la Intifada Al Aqsa 
«En la otra Intifada ocurrieron muchas cosas con las mujeres jóvenes que participaron en política (estuvieron en cárceles, fueron violadas, se involucraron en la resistencia con hombres, tomaban posiciones de liderazgo....). Las rechazaron, la sociedad no tuvo piedad con ellas por culpa de la tradición. Las mujeres fueron marginadas en la sociedad si participaban activamente con un discurso político. Incluso el movimiento nacional ha sido marginalizado, ya que la Autoridad lleva las riendas de este levantamiento».

\subsubsection{X, 38 años}

Madre de tres hijos, vive en Nablus, estudió en Damasco y, en uno de sus regresos a Palestina de vacaciones, la encarcelaron y no pudo terminar sus estudios. Participó durante la primera Intifada en la educación popular, una estructura paralela que trataba de suplir las clases en guarderías, colegios y universidades que habían sido cerrados por el ejército de ocupación. Dice que para acabar con el conflicto se ha de dar al pueblo palestino el derecho a tener un Estado independiente, como los demás países del mundo, y Jerusalén como capital. Si estas dos condiciones son respetadas, el Estado de Israel conocerá la paz automáticamente. Pero Israel no quiere la paz ni para su pueblo ni para el nuestro. Desea: «libertad, independencia y seguridad para nuestro pueblo, poder educar a mis hijos en un ambiente psicológica y socialmente sano lejos de lo que están viviendo ahora, y por último, paz y seguridad para todos los pueblos del mundo, que nadie sufra como nosotros».

\subsubsection{X, 44 años}

Vive en el campo de refugiados de Balata, Nablus, donde nació. Tiene tres hijos, perdió a su marido en la primera Intifada, desde entonces trabaja para alimentar a sus hijos.

«Para solucionar este conflicto es necesario: la reunificación de la nación árabe, llevar a cabo las decisiones internacionales sin retrasos y regresar al Islam y educar a nuestros hijos en paz. Si gobernara, cambiaría los métodos de esta Intifada y varias cosas de la Autoridad palestina. Si pudiera, haría que dimitieran todos los jefes de los países árabes, ya que su participación en el conflicto no es suficiente ni necesaria y encima se aprovechan de ello... Las mujeres que conozco participaron más en la otra Intifada, en esta lo que hacemos mucho es ayudar psicológicamente a las familias de los mártires, a levantar el ánimo, a ayudar a la gente necesitada de comida, medicamentos».

»Deseo el retorno de todos los refugiados, que Jerusalén sea la capital de Palestina y que conozcamos de una vez un régimen democrático, islámico, humano y sin discriminación.»

\section{CONCLUSIONES}

Existen muchas iniciativas de mujeres que reclaman el final de los conflictos y la violencia. Cada vez se incluye más a la mujer como objeto activo para la paz y no sólo como víctima. Las mujeres entrevistadas coinciden en que su presencia es menor en esta Intifada Al-Aqsa, pues el nivel de violencia es mu- 
cho mayor y las hace más vulnerables. No por ello tienen que ser vistas como víctimas sino como objetos activos, pues desempeñan una labor muy importante en el mantenimiento del tejido social y de las relaciones familiares. Ellas mantienen las familias en ausencia de los hombres, cuidan de los heridos, de la reducida economía familiar, se ocupan de los prisioneros y organizan en la medida de sus posibilidades clases en domicilios particulares para que sus hijos puedan seguir educándose. Sus actividades se ven en parte muy limitadas por el alto índice de fertilidad que se incrementa durante el conflicto.

El miedo que se ha instalado en todas las familias debido a la falta de protección por parte de la ANP y los ataques israelíes hace que éstas se vuelvan excesivamente protectoras, sobre todo los padres respecto a sus hijas. Esto repercute especialmente en las jóvenes, que dejan de ir a la universidad o los colegios si han de pasar por situaciones de peligro. Otro factor que influye en el abandono de los estudios por las mujeres jóvenes es la cada vez más reducida economía familiar, ya que en situaciones de carestía dejan de estudiar en favor de sus hermanos.

Experimentan también un retroceso en sus derechos como mujeres. Los casamientos precoces se vuelven a llevar a cabo, pues son considerados una manera de tener asegurado el honor de la familia en situaciones de crisis. La violencia de género ha aumentado en estos tres últimos años debido a la frustración de los hombres que no pueden ejercer su rol tradicional de protectores como en toda sociedad patriarcal.

La religiosidad y el conservadurismo están en alza. La falta de funcionamiento de la ANP hace que la gente se vuelque hacia los servicios sociales que ofrecen los grupos islamistas, que suelen actuar con mucha más eficacia ya que todo conflicto les beneficia. Hay un gran desencanto con los líderes políticos en general. Las mujeres se van alejando de posiciones de liderazgo. Aun así, y a pesar del conservadurismo en alza, existe un rayo de esperanza y es que estas mujeres están accediendo a estudios más elevados, lo cual representa un caldo de cultivo positivo para futuros cambios.

Habría que destacar también el esfuerzo que hacen las asociaciones de mujeres para que se escuchen sus voces, a pesar de las dificultades de la situación y de la primacía de las ideas nacionales sobre la defensa de sus derechos específicos. Sus voces delatan otra forma de acercamiento al conflicto, otra manera de solucionarlo. El hecho de estar imbuidas en una cultura patriarcal cuyos valores encuadran a la mujer en la cultura del cuidado, dando un enfoque prioritario a la vida, es una gran fuente de recursos para una cultura de paz, para otra visión de la solución del conflicto. 